\title{
Short communication: $N$-Acetylcysteine-mediated modulation of antibiotic susceptibility of bovine mastitis pathogens
}

\author{
F. Yang, L. H. Liu, X. P. Li, J. Y. Luo, Z. Zhang, Z. T. Yan, S. D. Zhang, and H. S. Li ${ }^{1}$ \\ Key Lab of New Animal Drug Project, Key Laboratory of Veterinary Pharmaceutical Development, Ministry of Agriculture, \\ Lanzhou Institute of Husbandry and Pharmaceutical Sciences of Chinese Academy of Agricultural Science, Lanzhou 730050, China
}

\begin{abstract}
The aim of this study was to investigate the effects of $N$-acetylcysteine (NAC) on antibiotic susceptibility of bovine mastitis pathogens including Staphylococcus aureus, Streptococcus dysgalactiae, Escherichia coli, and Streptococcus agalactiae. Minimum inhibitory concentrations (MIC) were tested by the agar-based E-test method. The presence of $10 \mathrm{~m} M \mathrm{NAC}$ reduced the MIC of penicillin and ampicillin but enhanced the MIC of erythromycin and ciprofloxacin for all of the strains. In addition, NAC-mediated modulation of MIC of kanamycin, tetracycline, and vancomycin was diverse, depending on the target bacterial pathogen and antibiotic being used. The results suggest that NAC is an important modulator of antibiotic activity against the major bovine mastitis pathogens.
\end{abstract}

Key words: $N$-acetylcysteine, bovine mastitis, pathogen, antibiotic susceptibility

\section{Short Communication}

Bovine mastitis is one of the most costly diseases affecting the dairy industry worldwide (Perreten et al., 2013). Although mastitis can be caused by 137 different microorganisms (Watts, 1988), Staphylococcus aureus, Streptococcus dysgalactiae, Escherichia coli, and Streptococcus agalactiae are the main etiological agents commonly associated with the disease (Nair et al., 2005). To date, antibiotic therapy is the standard treatment of mastitis. However, the results of this therapy have been disappointing due to the misuse of antibiotics (Pereira et al., 2011; Barrero et al., 2014).

$\mathrm{N}$-Acetylcysteine (NAC) is a mucolytic agent that disrupts disulfide bonds in mucus and reduces the viscosity of secretions (El-Feky et al., 2009). Based on these characteristics, NAC has been widely used as an adjuvant in combination with antibiotics during medical treatment of bacterial infectious diseases including

Received December 13, 2015.

Accepted February 16, 2016.

${ }^{1}$ Corresponding author: lihsheng@sina.com chronic bronchitis, vascular catheter-related infection, and urinary tract infection (Marchese et al., 2003; Olofsson et al., 2003; Aslam et al., 2007). However, the effect of NAC on bovine mastitis pathogens has not been studied. The aim of this study was to investigate the effects of NAC on antibiotic susceptibility of Staph. aureus, Strep. dysgalactiae, E. coli, and Strep. agalactiae isolated from bovine mastitis cases.

The Staph. aureus, Strep. dysgalactiae, E. coli, and Strep. agalactiae strains were isolated from subclinical bovine mastitis in Gansu province in China during 2015. Mastitis infection was confirmed by the California mastitis test. Identification was performed by morphological characterization and biochemical testing as previously described (Cressier and Bissonnette, 2011). Minimum inhibitory concentrations of penicillin, ampicillin, erythromycin, kanamycin, tetracycline, ciprofloxacin, and vancomycin were determined by the E-test (BioMerieux, Marseille, France) method (Liu et al., 2014). Antimicrobial agent concentrations ranged from 0.002 to $32 \mu \mathrm{g} / \mathrm{mL}$ for penicillin and ciprofloxacin, and 0.016 to $256 \mu \mathrm{g} / \mathrm{mL}$ for ampicillin, erythromycin, kanamycin, tetracycline, and vancomycin.

The effects of NAC (Sigma-Aldrich, Lyon, France) on antibiotic susceptibility of pathogens to 7 antibiotics belonging to different groups were studied by measuring their MIC in the presence and absence of $10 \mathrm{mM}$ NAC in the medium, respectively. Antibiotic susceptibility of 2 Staph. aureus strains (LZ 0215, LZ 84184), 2 Strep. dysgalactiae strains (LZ 717, LZ 211), 2 E. coli strains (LZ 2552, LZ 282), and 2 Strep. agalactiae strains (LZ 17, LZ 21) were determined in this study. The presence of $10 \mathrm{~m} M \mathrm{NAC}$ did not affect the growth of these strains. The experiments were carried out at least twice, and the representative results are mentioned here.

The effects of NAC on antibiotic susceptibility of Staph. aureus and Strep. dysgalactiae are shown in Table 1, and E. coli and Strep. agalactiae are shown in Table 2. In the case of $\beta$-lactam antibiotics, the MIC of both penicillin and ampicillin decreased for all of the strains in the presence of NAC. Conversely, NAC increased the MIC of erythromycin and ciprofloxacin for all of the strains. It also led to reduction in MIC of 
Table 1. Effect of $N$-acetylcysteine $\left(\mathrm{NAC}^{1}\right)$ on susceptibility of Staphylococcus aureus and Streptococcus dysgalactiae to different antibiotics, as measured by MIC $(\mu \mathrm{g} / \mathrm{mL})$

\begin{tabular}{|c|c|c|c|c|c|c|c|c|}
\hline \multirow{2}{*}{ Antibiotic } & \multicolumn{4}{|c|}{ Staph. aureus } & \multicolumn{4}{|c|}{ Strep. dysgalactiae } \\
\hline & \multicolumn{2}{|c|}{ LZ 0215} & \multicolumn{2}{|c|}{ LZ 84184} & \multicolumn{2}{|c|}{ LZ 717} & \multicolumn{2}{|c|}{ LZ 211} \\
\hline Penicillin & 1.5 & 0.38 & 0.5 & 0.25 & 1.5 & 0.75 & 0.016 & 0.004 \\
\hline Ampicillin & 2 & 0.25 & 0.75 & 0.5 & 0.75 & 0.25 & 0.032 & $<0.016$ \\
\hline Erythromycin & 0.094 & 3 & 0.064 & 8 & 0.75 & 3 & 0.032 & 0.064 \\
\hline Ciprofloxacin & 0.19 & 0.25 & 1 & 1.5 & 0.5 & 1.5 & 0.75 & 1 \\
\hline Vancomycin & 1.5 & 1.5 & 1.5 & 1.5 & 2 & 2 & 0.75 & 0.75 \\
\hline
\end{tabular}

${ }^{1}$ In each case, the final NAC concentration was $10 \mathrm{mM}$.

tetracycline for all of the strains except that of E. coli. Similarly, the MIC of kanamycin decreased for Strep. agalactiae and Strep. dysgalactiae strains but increased for Staph. aureus and E. coli strains in the presence of NAC. In addition, changes in vancomycin MIC were not observed in Staph. aureus, Strep. dysgalactiae, and $E$. coli strains at the presence of NAC, although it resulted in a reduction in MIC of vancomycin against Strep. agalactiae.

The presence of NAC enhances the efficacy of $\beta$-lactams antibiotics against all of the strains, while it gives protection against erythromycin and ciprofloxacin. These data are similar to those reported by Goswami and Jawali (2010). However, in our study, it is interesting that NAC reduced the antibacterial activity of kanamycin against pathogens belonging to Streptococcus spp. alone. And for tetracycline, the presence of NAC decreased the antibacterial activity against grampositive bacteria but enhanced that against gram-negative bacteria. In addition, NAC gives protection against vancomycin for Strep. agalactiae alone. These findings suggest that the effects of NAC on bacterial antibiotic susceptibility are significantly associated with bacterial species, shape, and structure. It was reported that
NAC in combination with fosfomycin and tigecycline displayed opposite effects on bacterial biofilm formation (Marchese et al., 2003; Aslam et al., 2007). The bacteria enclosed in biofilm became 10 to 1,000 times more tolerant to antibiotics than equivalent planktonic cultures (Mah and O'Toole, 2001). In this study, it is possible that NAC-mediated modulation of antibiotic susceptibility against the pathogens may be mediated by biofilm-forming ability, and the specific mechanisms are being explored in our laboratory.

In conclusion, the present study indicates that NAC is an important modulator of antibiotic activity against the major bovine mastitis pathogens. A combination of $\beta$-lactam antibiotics and NAC is recommended during antibiotic therapy of bovine mastitis caused by these major pathogens.

\section{ACKNOWLEDGMENTS}

This study was supported by the Special Fund of Chinese Central Government for Basic Scientific Research Operations in Commonwealth Research Institutes (No. 1610322015007) and the Natural Science Foundation of Gansu Province (No. 145RJYA311, China).

Table 2. Effect of $N$-acetylcysteine $\left(\mathrm{NAC}^{1}\right)$ on susceptibility of Escherichia coli and Streptococcus agalactiae to different antibiotics, as measured by $\mathrm{MIC}(\mu \mathrm{g} / \mathrm{mL})$

\begin{tabular}{|c|c|c|c|c|c|c|c|c|}
\hline Antibiotic & \multicolumn{4}{|c|}{ E. coli } & \multicolumn{4}{|c|}{ Strep. agalactiae } \\
\hline Penicillin & $>32$ & 32 & $>32$ & 12 & 0.047 & 0.016 & 0.032 & 0.016 \\
\hline Ampicillin & 2 & 1.5 & 3 & 1 & 0.094 & $<0.016$ & 0.064 & $<0.016$ \\
\hline Erythromycin & 16 & $>256$ & 48 & $>256$ & 0.032 & 0.125 & 0.047 & 0.25 \\
\hline Ciprofloxacin & 0.004 & 0.012 & 0.004 & 0.012 & 0.5 & 1.5 & 0.5 & 1.5 \\
\hline Vancomycin & $>256$ & $>256$ & $>256$ & $>256$ & 1.5 & 0.75 & 1 & 0.5 \\
\hline
\end{tabular}

${ }^{1}$ In each case, the final NAC concentration was $10 \mathrm{mM}$. 


\section{REFERENCES}

Aslam, S., B. W. Trautner, V. Ramanathan, and R. O. Darouiche. 2007. Combination of tigecycline and $\mathrm{N}$-acetylcysteine reduces biofilm-embedded bacteria on vascular catheters. Antimicrob. Agents Chemother. 51:1556-1558.

Barrero, M. A., P. A. G. Pietralonga, D. G. G. Schwarz, A. S. Junior, S. O. Paula, and M. A. S. Moreira. 2014. Effect of the inhibitors phenylalanine arginyl $\beta$-naphthylamide (PAßN) and 1-(1-naphthylmethyl)-piperazine (NMP) on expression of genes in multidrug efflux systems of Escherichia coli isolates from bovine mastitis. Res. Vet. Sci. 97:176-181.

Cressier, B., and N. Bissonnette. 2011. Assessment of an extraction protocol to detect the major mastitis-causing pathogens in bovine milk. J. Dairy Sci. 94:2171-2184.

El-Feky, M. A., M. S. El-Rehewy, M. A. Hassan, H. A. Abolella, R. M. Abd El-Baky, and G. F. Gad. 2009. Effect of ciprofloxacin and $\mathrm{N}$-acetylcysteine on bacterial adherence and biofilm formation on ureteral stent surfaces. Pol. J. Microbiol. 58:261-267.

Goswami, M., and N. Jawali. 2010. N-Acetylcysteine-mediated modulation of bacterial antibiotic susceptibility. Antimicrob. Agents Chemother. 54:3529-3530.

Liu, H., T. H. Taylor, K. Pettus, and D. Trees. 2014. Assessment of value of E-test as an alternative to agar dilution for Neisseria gonorrhoeae antimicrobial susceptibility testing. J. Clin. Microbiol. $52: 1435-1440$
Mah, T. F. C., and G. A. O'Toole. 2001. Mechanisms of biofilm resistance to antimicrobial agents. Trends Microbiol. 9:34-39.

Marchese, A., M. Bozzolasco, L. Gualco, E. A. Debbia, G. C. Schito, and A. M. Schito. 2003. Effect of fosfomycin alone and in combination with $\mathrm{N}$-acetylcysteine on $E$. coli biofilms. Int. J. Antimicrob. Agents 22:95-100.

Nair, M. K. M., J. Joy, P. Vasudevan, L. Hinckley, T. A. Hoagland, and K. S. Venkitanarayanan. 2005. Antibacterial effect of caprylic acid and monocaprylin on major bacterial mastitis pathogens. J. Dairy Sci. 88:3488-3495.

Olofsson, A. C., M. Hermansson, and H. Elwing. 2003. N-acetyl-Lcysteine affects growth, extracellular polysaccharide production, and bacterial biofilm formation on solid surfaces. Appl. Environ. Microbiol. 69:4814-4822.

Pereira, U. P., D. G. S. Oliveira, L. R. Mesquita, G. M. Costa, and L. J. Pereira. 2011. Efficacy of Staphylococcus aureus vaccines for bovine mastitis: A systematic review. Vet. Microbiol. 148:117-124.

Perreten, V., A. Endimiani, A. Thomann, J. R. Wipf, A. Rossano, M. Bodmer, A. Raemy, K. A. Sannes-Lowery, D. J. Ecke, R. Sampath, R. A. Bonomo, and C. Washington. 2013. Evaluation of PCR electrospray-ionization mass spectrometry for rapid molecular diagnosis of bovine mastitis. J. Dairy Sci. 96:3611-3620.

Watts, J. L. 1988. Etiological agents of bovine mastitis. Vet. Microbiol. 16:41-66. 